\title{
Population dynamics and potential management of bowfin (Amia calva) in the upper Mississippi River
}

\author{
By J. D. Koch ${ }^{1}$, M. C. Quist ${ }^{1}$, K. A. Hansen ${ }^{2}$ and G. A. Jones ${ }^{2}$ \\ ${ }^{1}$ Department of Natural Resource Ecology and Management, Iowa State University, Ames, IA; ${ }^{2}$ Iowa Department of Natural \\ Resources, Bellevue, IA, USA
}

\section{Summary}

Bowfin Amia calva are a common species throughout the Mississippi River basin. Although they are generally regarded as a 'rough' fish by management agencies and anglers, commercial harvest for their roe has increased in the upper Mississippi River (UMR) basin. Unfortunately, bowfin population dynamics have not received extensive study, resulting in a lack of information that can be used to guide management efforts, particularly in the UMR. The purpose of this study was to investigate the age structure, growth, and reproductive ecology (e.g. age at maturity, fecundity) of bowfin in Pools 11 and 13 of the UMR during the spring of 2007. 118 bowfin from Pool 11 and 138 bowfin from Pool 13 were sampled using modified fyke nets and electrofishing. Size structure, age structure, and growth were similar and sex ratios were near 1:1 in both pools. Female bowfin matured at age 3 and had gonadosomatic index (GSI) values around 9; male bowfin matured at age 2 and had GSI values near 1. Total annual mortality of age- 4 and older fish was around 35\% for both populations. In both pools, rates of total annual mortality of males were approximately $10 \%$ higher than those of females. Growth overfishing occurred in a simulated population with a 500-mm minimum length limit. Recruitment overfishing occurred with 500-mm, 559-mm, and 584-mm limits at moderate to high levels of exploitation; a $635-\mathrm{mm}$ minimum prevented recruitment overfishing at all levels of exploitation.

\section{Introduction}

Bowfin Amia calva are a Holostean fish that is the last extant species in its order (Amiiformes) and family (Amiidae). Bowfin have many common names (e.g. dogfish, mudfish, grindel, and choupique) that describe its aggressive behavior and affinity for shallow, turbid, highly-vegetated habitats. Traditionally, bowfin have been considered an undesirable species that competes with more desirable sport or commercial species; however, Scarnecchia (1992) suggested that the value of A. calva be reappraised for their contribution to ecosystem stability and function. Changes in the attitudes of some biologists have emerged as bowfin have been used in the management of other fishes. For instance, Mundahl et al. (1998) stocked bowfin into a Minnesota lake to decrease densities of stunted bluegill Lepomis macrochirus. Unfortunately, $A$. calva did not reproduce in the system and did not exhibit the high predation rates needed to improve growth rates and size structure of the bluegill population (Mundahl et al., 1998). Although many anglers consider bowfin a nuisance, some hold bowfin in high regard due to its purported strength, endurance, and fighting ability (Pflieger, 1997). In fact, angling groups (e.g. the Bowfin Anglers Group) have formed to promote bowfin angling and dispel myths regarding the species.

Bowfin are also an increasingly important commercial species. In the upper Mississippi River (UMR), there have been periodic peaks in harvest of its flesh. From 1953 to 2005, an average of $5174 \mathrm{~kg}$ per year $(\mathrm{SE}=419 \mathrm{~kg}$ ) was harvested from the UMR (M. Marron, Wisconsin Department of Natural Resources, unpublished information). Of this harvest, $69 \%$ was from Pools 7 to 11 . A maximum of $19569 \mathrm{~kg}$ of bowfin flesh was harvested from the UMR in 1998. Although a small market for bowfin is present in the UMR, a much greater market for bowfin flesh exists outside the UMR. In 2003, commercial harvest of its flesh in Louisiana totaled over $92,000 \mathrm{~kg}$, valued at more than US\$128,000 (Southwick and Allen, 2005). Although there has been a historic demand for bowfin flesh in southern portions of the United States, it was not until the early 1990s that a developing bowfin caviar market raised concerns regarding overharvest and population declines in Louisiana (Davis, 2006). As a result, a 559-mm minimum length limit was implemented in 1991 to regulate commercial harvest in Louisiana. Commercial harvest of bowfin in the UMR is not currently regulated with length limits. A. calva is typically collected with fyke nets that are constructed with large-mesh leads (i.e. gill nets) that function as entanglement gear. In the Atchafalaya River basin of Louisiana, sinking gill nets, hoop nets, and trot lines are used to capture bowfin, depending on habitat and flow conditions (Davidson et al., 1991). Currently, commercial harvesters in the UMR basin sell the unprocessed roe for around US\$55 per kg, whereas the value of processed bowfin roe in the lower Mississippi River basin is around $\$ 80$ per $\mathrm{kg}$ (G. Scholten, Tennessee Wildlife Resources Agency, personal communication).

Despite their wide distribution and importance in aquatic systems, few studies on bowfin have been conducted; research has generally focused on food habits and potential effects on fish assemblages (e.g. Scott, 1938; Lagler and Hubbs, 1940; Lagler and Applegate, 1942; Stacy et al., 1970; Dugas et al., 1976; Mundahl et al., 1998). The phylogeny and physiology of bowfin has also received considerable study because bowfin and gars (family Lepisosteidae) represent a unique link between primitive fishes and teleosts (e.g. Horn and Riggs, 1973; Daxboeck et al., 1981; Ballard, 1986). The few studies describing dynamics of bowfin populations have been conducted outside the UMR basin. Davidson et al. (1991) and Davis (2006) examined the structure of populations in Louisiana, and Holland (1964) studied the ecology of bowfin in southeastern Missouri. As commercial harvests increase, 
understanding the ecology and population dynamics and the potential effects of commercial harvest on their populations in the UMR is critical. As such, the objectives of this study were to describe population parameters of bowfin in Pools 11 and 13 of the UMR and evaluate the potential harvest restrictions needed to prevent overfishing of bowfin in the UMR.

\section{Methods}

\section{Study site}

The UMR is defined by the Upper Mississippi River Conservation Committee as the $1490 \mathrm{~km}$ portion of the Mississippi River between Hastings, Minnesota and Caruthersville, Missouri (Pitlo and Rasmussen, 2004). The UMR is impounded by 24 locks and dams that aid in the maintenance of a $2.7-\mathrm{m}$ deep and 122-m wide navigation channel (Hurley et al., 1987). Pool 11 extends $52 \mathrm{~km}$ from Guttenberg, Iowa downstream to Dubuque, Iowa and has a surface area of 8036 ha. Pool 13 encompasses 11,379 hectares and is the $55 \mathrm{~km}$ reach from Bellevue, Iowa to Clinton, Iowa. Both pools consist of main channel and channel border habitats as well as extensive networks of side channels and backwaters.

\section{Fish sampling and laboratory methods}

Bowfin were collected from Pools 11 and 13 of the UMR in April 2007 using modified fyke nets and boat-mounted pulsedDC electrofishing. The nets were constructed of $19-\mathrm{mm}$ bar mesh with $0.75 \times 1.5-\mathrm{m}$ frames, a $12-\mathrm{m}$ lead, and two throats. Bowfin were measured (total length, TL) to the nearest millimeter and weighed to the nearest gram. All bowfin were euthanized and transported to the laboratory where their sex was determined and gonads were extracted and weighed; the pectoral fin rays were collected for age and growth analyses. Fin rays were clipped as close as possible to the pectoral girdle, placed in individually-numbered scale envelopes and allowed to air dry then mounted in epoxy (Koch and Quist, 2007) and sectioned with a Buehler Isomet low-speed saw (Buehler Inc., Lake Bluff, Illinois). Three 0.6-mm sections were cut from the encapsulated fin rays to ensure at least one high-quality section for aging. Fin ray sections were aged with the aid of a compound light microscope equipped with a camera linked to an image analysis system (Image-Pro Plus; Media Cybernetics, Silver Springs, Maryland). Annuli were measured from all fin rays and mean back-calculated lengths at age were estimated using the Dahl-Lea method (DeVries and Frie, 1996):

$L_{i}=L_{c}\left(R_{i} / R_{c}\right)$,

where $L_{i}$ is the length at annulus $i, L_{c}$ is the length at capture, $R_{i}$ is the fin ray radius at annulus $i$, and $R_{c}$ is the fin ray radius at capture. A von Bertalanffy growth function was also used to describe growth:

$L_{t}=L_{\infty}\left(1-e^{-K\left(t-t_{0}\right)}\right)$,

where $L_{t}$ is the length at time $t, L_{\infty}$ is the theoretical maximum length, $K$ is the growth coefficient (the rate at which fish approach $L_{\infty}$ ), and $t_{0}$ is the time when length would theoretically equal $0 \mathrm{~mm}$. The gonadosomatic index (GSI) was calculated as:

\section{GSI $=100$ (weight of gonads/total weight of fish).}

Fecundity was estimated by weighing and counting three subsamples of eggs from each third of both preserved ovaries
(18 subsamples per fish). The number of eggs per gram for each subsample was calculated and averaged for each third of each ovary. The resulting average number of eggs per gram was then multiplied by the weight of each respective third and summed for each ovary to obtain a total estimate of fecundity for each ovary. Estimates for each ovary were summed to obtain a total fecundity estimate for each fish. Linear regression was used to develop a fecundity-length equation. Total annual mortality $(A)$ was estimated using a weighted catch curve that was limited to those ages considered fully recruited to our sampling gear (age 4 and older in Pool 11 and age 5 and older in Pool 13) (Van Den Avyle and Hayward, 1999; Miranda and Bettoli, 2007).

\section{Population simulations}

Because female bowfin are the target of the fishery and thus the primary management concern, the effects of minimum length limits on harvest of the females were simulated using a Beverton-Holt yield-per-recruit model. Reproductive parameters, growth, maximum age, and the length-weight relationship from female bowfin were specified in the model. Data were combined across study pools for the models because population parameters were similar between pools, and because populations would likely be managed with the same minimum length limit. Conditional natural mortality $(\mathrm{cm}$; mortality that occurs in absence of fishing mortality) was modeled at $20 \%$ and conditional fishing mortality ( $c f$; mortality due to fishing in absence of natural mortality) was modeled at levels varying from $0 \%$ (an unexploited population) to $90 \%$ to evaluate how the simulated population responded to differing levels of exploitation. Simulations were conducted using four minimum length limits (500-mm, 559-mm, 584-mm, and 635-mm). A cm of $20 \%$ was used because it best approximated the observed mortality rate of female bowfin in the UMR. The $500-\mathrm{mm}$ length limit represented a scenario of unregulated harvest and was the approximately length of the smallest mature females (i.e. possessing marketable roe) collected in our samples. The $559-\mathrm{mm}$ limit is the minimum for commercial bowfin harvest in Louisiana and would protect approximately $10 \%$ of the mature females in the population (based on our sample). The $584-\mathrm{mm}$ and $635-\mathrm{mm}$ minimum would protect $25 \%$ and $50 \%$ of the mature females, respectively. Yield was plotted against exploitation to evaluate the likelihood of growth overfishing. Growth overfishing occurs when yield decreases with increasing levels of exploitation because fish are harvested before they are able to realize their full growth potential (Slipke and Maceina, 2001).

The potential for recruitment overfishing was also examined. Recruitment overfishing occurs when fish are harvested from a population before they are able to replace themselves, thus leading to a population decline and possible stock collapse. Recruitment overfishing is traditionally examined by assessing the reproductive potential of an exploited population relative to that of an unexploited population (Goodyear, 1993; Mace and Sissenwine, 1993). Spawning potential ratio (SPR) represents the proportion of lifetime egg production of an exploited population compared to that of an unexploited population and calculated as:

$\mathrm{SPR}=\left[100\left(P_{\text {exploited }} / P_{\text {unexploited }}\right)\right]$

where $P$ is the lifetime egg production of a cohort of recruits. Overharvest was interpreted to have an increased likelihood of 
occurrence at an SPR of 30\% (Goodyear, 1993). All population simulations were conducted in Fisheries Analysis and Simulation Tools (FAST; Slipke and Maceina, 2001) with an initial population of 1000 recruits.

\section{Results}

A total of 256 (Pool 11, N = 118; Pool 13, $\mathrm{N}=138$ ) bowfin varying in length from $392 \mathrm{~mm}$ to $807 \mathrm{~mm}$ and from $504 \mathrm{~g}$ to $4505 \mathrm{~g}$ in weight were collected. Size structure was generally similar between pools (Fig. 1); however, the median length was slightly smaller in Pool 11 (592 mm) than in Pool 13 (609 mm). The length-weight relationship was also similar in both pools. The pooled length-weight regression $\left(r^{2}=0.94 ; \mathrm{P}<0.0001\right)$ describing the relationship between length and weight was $\log _{10}$ weight $=-4.895+2.939\left(\log _{10}\right.$ length $)$. In both pools, sex ratios were approx. 1:1 (Pool $11=1.2$ males per female; Pool $13=1.1$ males per female). The sex of three bowfin could not be determined. Female bowfin were generally larger than males, with females having a median length of $622 \mathrm{~mm}$ compared to $591 \mathrm{~mm}$ for males.

Our sampling methods were not effective for capturing young bowfin. Only three females younger than age 4 (two age- 3 and one age- 2 fish) were collected. Both age- 3 females were sexually mature, but not the age- 2 female. The mean GSI of mature female bowfin across pools was $9.5(\mathrm{SE}=0.3)$ and varied from 1.9 to 14.8. All male bowfin appeared to be mature and had a mean GSI of $1.0(\mathrm{SE}=0.1)$. Fecundity of the mature females varied from 9498 to 110086 (Fig. 2).

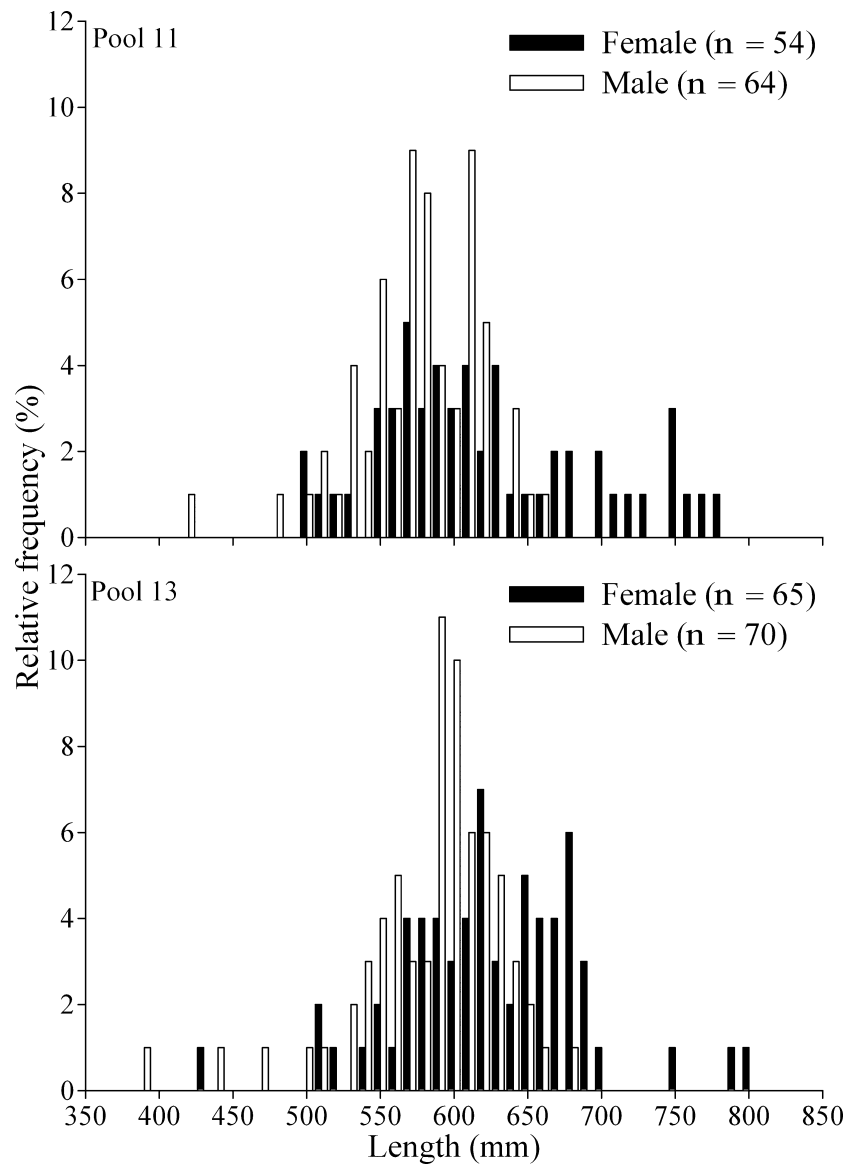

Fig. 1. Length frequency distributions of bowfin (A. calva) sampled from Pools 11 and 13, upper Mississippi River, 2007

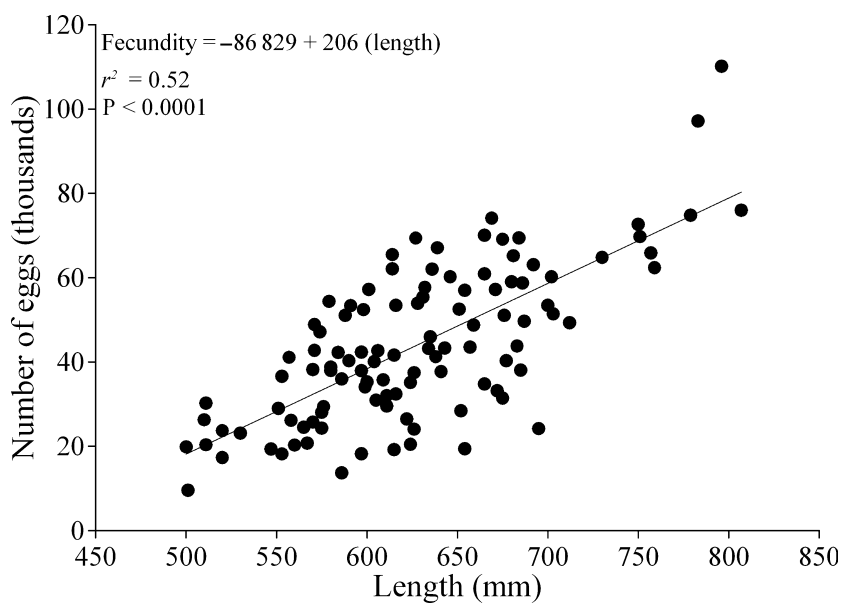

Fig. 2. Fecundity of gravid female bowfin (A. calva) sampled from Pools 11 and 13, upper Mississippi River, 2007

Although the age structure of bowfin from Pool 11 contained a higher proportion of individuals less than four years of age $(32 \%)$ than the sample from Pool $13(13 \%)$, estimates of total annual mortality for the two populations were similar (Fig. 3). In both pools, total annual mortality estimates for males were approximately $10 \%$ higher than those for females. Female bowfin exhibited greater longevity than male bowfin. The maximum age of females was 13 years in Pool 11 and 12 years in Pool 13, whereas the maximum age

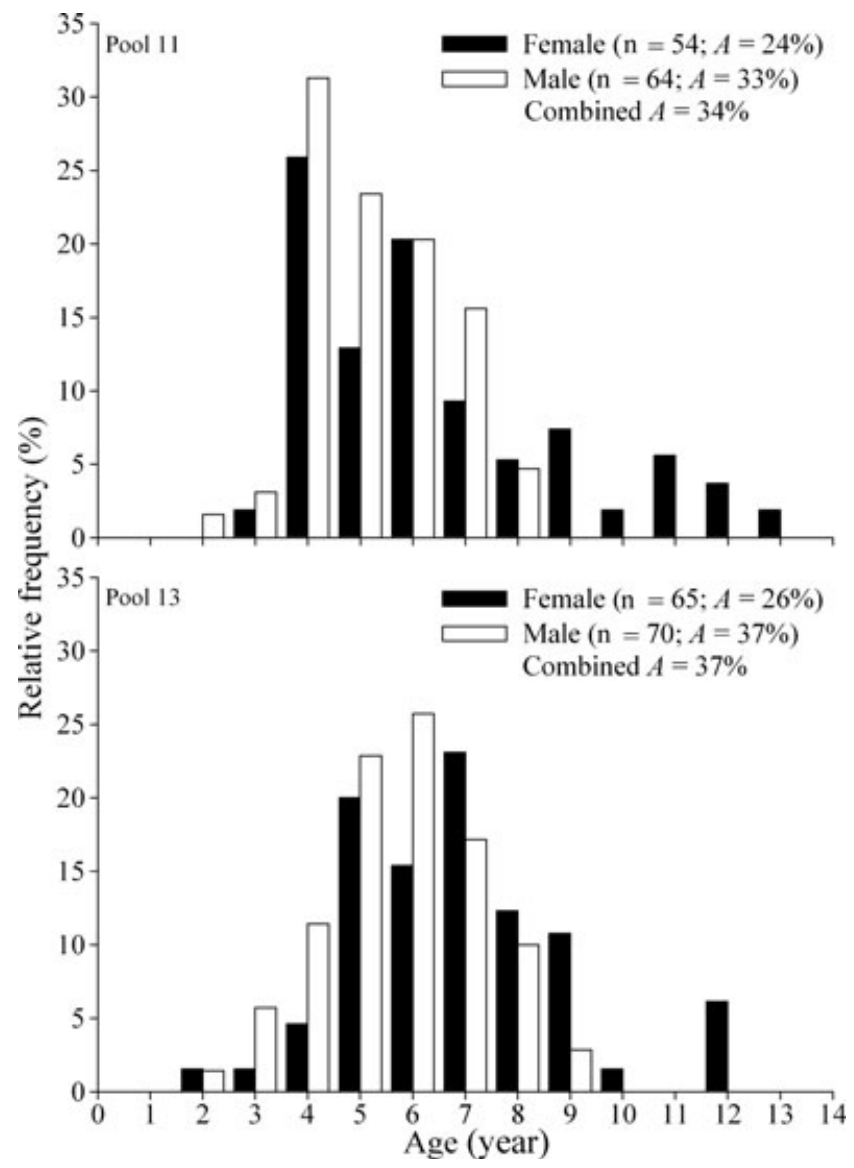

Fig. 3. Age frequency distributions of bowfin (A. calva) sampled from Pools 11 and 13, upper Mississippi River, 2007. Total annual mortality $(A)$ provided for each pool and sex. Mortality estimated for ages considered fully recruited to the sampling gear (age 4 and older in Pool 11; age 5 and older in Pool 13) 


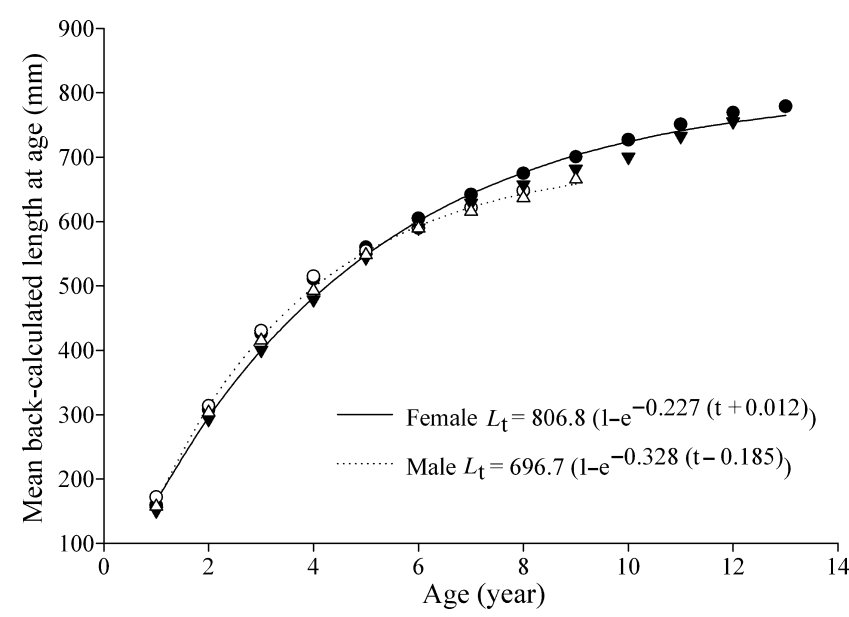

Fig. 4. Predicted von Bertalanffy growth curves and mean backcalculated lengths at age of bowfin (A. calva) sampled from Pool 11 (circles) and Pool 13 (triangles), upper Mississippi River, 2007. Mean back-calculated lengths for males (open symbols) and females (solid symbols). Equations represent pooled, sex-specific von Bertalanffy models (pools 11 and 13 combined by sex)

of males was 8 years in Pool 11 and 9 years in Pool 13. Growth was similar between pools (Fig. 4) as well as between sexes. The pooled von Bertalanffy model describing growth of all bowfin in the study area was $L_{t}=800.2\left(1-e^{0.229(t+0.056)}\right)$.

Simulated yields were higher for less-restrictive length limits at low levels of exploitation (Fig. 5). The three most restrictive

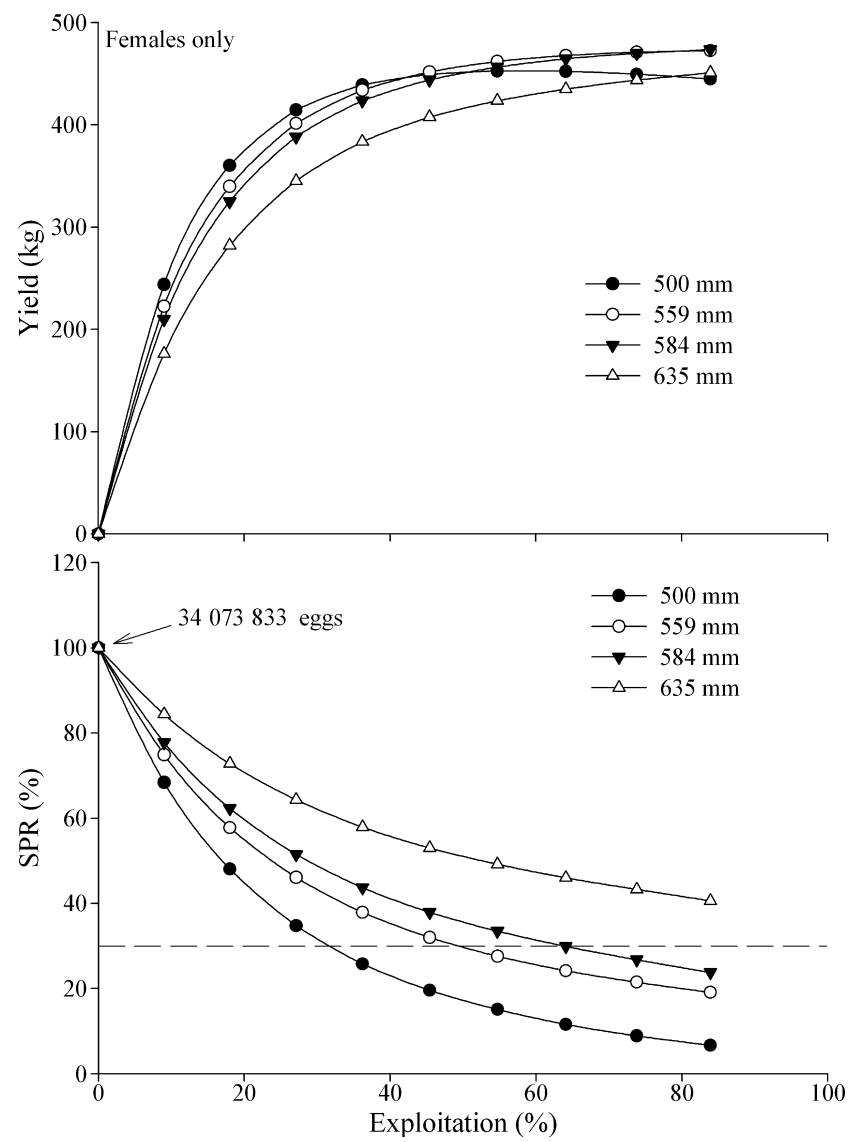

Fig. 5. Simulated yields (top panel) and spawning potential ratios (SPR; bottom panel) for female bowfin ( $A$. calva) populations, upper Mississippi River, with $20 \%$ conditional natural mortality rate. Simulations conducted with four minimum length limits $(500 \mathrm{~mm}$, $559 \mathrm{~mm}, 584 \mathrm{~mm}$, and $635 \mathrm{~mm}$ ) minimum length limits prevented growth overfishing in the simulations, but growth overfishing occurred with the $500-\mathrm{mm}$ limit at approximately $65 \%$ exploitation. Spawning potential ratios decreased to levels below $30 \%$ in the simulations with the three least restrictive limits. When recruitment overfishing occurred (SPR $\leq 30 \%$ ) with a 500 -mm length limit, approximately $10 \%$ more lifetime eggs were protected by the $559-\mathrm{mm}$ limit and SPR nearly doubled when the minimum was increased to $635 \mathrm{~mm}$. Our models suggest recruitment overfishing is not a current concern in the UMR, but is possible at moderate to high levels of exploitation.

\section{Discussion}

Few studies have described the growth of bowfin, and there are few consistencies among those studies. For example, mean back-calculated lengths at ages 1 to 7 reported by Holland (1964) were similar to those described in the current study; however, our estimates of mean back-calculated length at age were considerably smaller after age 7 . In comparison to mean length at age data reported by Davis (2006), our estimated lengths for younger ages of bowfin were substantially smaller. Such differences in growth estimates may be a result of small sample sizes of young and old year-classes in all studies, spatial variation in growth, or dissimilarities in methods used to estimate bowfin growth. For instance, Holland (1964) and Davis (2006) used gular plates to age bowfin; whereas we used sectioned pectoral fin rays, which provide more precise age estimates than the gular plates (Koch et al., in press).

Male bowfin exhibited lower longevity and higher rates of total annual mortality than female bowfin in the UMR. Our results are corroborated by Holland (1964), who suggested that the males experience higher levels of annual mortality than females in southeast Missouri. Additionally, Davis (2006) reported that female bowfin exhibit greater longevity than male bowfin in Louisiana. In the Davis (2006) study, the maximum age of females collected was 10 years, whereas the maximum age of males was 6 years. Furthermore, mean age of female bowfin (4.7 years) was significantly higher than that of male bowfin (3.5 years; Davis, 2006). The specific mechanism for this pattern is unknown, but higher mortality rates of the males may be due to their reproductive strategy, which includes building a nest and aggressively guarding fertilized eggs and the resulting juvenile bowfin until they reach about $100 \mathrm{~mm}$ in length (Reighard, 1940; Holland, 1964). While this strategy may increase the survival of progeny, territorial care by male fishes may increase adult male mortality rates (Gross and Sargent, 1985). Estimates of total annual mortality of bowfin in the UMR (34\% and $37 \%$ ) were substantially lower than those reported from Louisiana (58\%; Davis, 2006). Although differences in levels of total annual mortality between the two populations could be a result of the differing techniques used for age estimation, these are most likely due to differences in habitat conditions or exploitation.

The number of males and females collected in our study was nearly equal. In contrast, Holland (1964) and Davis (2006) reported populations containing more females, which the authors attributed to higher mortality rates of male bowfin. The higher proportion of males in our sample may have been biased by the season in which sampling occurred. Bowfin were sampled in April immediately prior to spawning, from areas that serve as spawning habitat. Thus, these areas were likely occupied by a disproportionate number of males. 
Bowfin may be less sensitive to harvest than other species harvested for their roe (e.g. Acipenserids and paddlefish Polyodon spathula), as they exhibit different life history strategies. For instance, female bowfin mature at a relatively early age (3 to 4 years) and spawn annually, whereas female sturgeon and paddlefish mature much later and have spawning periodicities of several years (Reed et al., 1992; Birstein, 1993; Boreman, 1997). In addition, susceptibility of bowfin to the effects of harvest may be minimized because they are not as long-lived as other species commercially harvested for roe. Long-lived species are generally adapted to protract their reproductive potential over their lifespan, making their populations highly susceptible to the effects of fishing (Birstein, 1993; Boreman, 1997). The maximum age of bowfin in our study was 13 years. Long-lived roe species such as shovelnose sturgeon Scaphirhynchus platorynchus and paddlefish can live in excess of 30 years (Scarnecchia et al., 1996; Morrow et al., 1998). Finally, bowfin are sexually dimorphic, and males are easily differentiated from females by an occelus near the caudal fin. Other species harvested for roe that are not sexually dimorphic may have increased harvest simply because males are harvested when fisherman are actually targeting females. The sexual dimorphism of $A$. calva allows commercial harvesters to select for one sex and thus avoid mortality of non-targeted bowfin. For example, because female bowfin are more valuable when carrying 'ripe' eggs in the spring, harvesters can discard females when fishing for the flesh market in an attempt to conserve the female proportion of the population for roe production. In effect, this practice may help maintain the reproductive potential of the population compared to other species harvested for roe. Another reason that sexual dimorphism may lessen the effects of harvest on bowfin populations is because individuals will not experience potential, delayed mortality due to egg-checking (an incision on the ventral surface of the fish to check for mature eggs). Commercial fishermen commonly egg-check paddlefish and sturgeons to differentiate between mature females and individuals that are not carrying marketable eggs (e.g. immature females and males).

Our results suggest overfishing of bowfin in the UMR is not currently a concern; however, if exploitation increases, implementation of harvest regulations (e.g. minimum length limits) may be required. If necessary, we recommend $635-\mathrm{mm}$ in the $\mathrm{UMR}$, as it prevents recruitment overfishing at all levels of exploitation without substantially decreasing yield. An important characteristic of our study is that we believe our results reflect two A. calva populations that are relatively unexploited. More often than not, commercially-exploited species are studied only after substantial harvest has raised concerns regarding sustainability of the fishery. This study provides preliminary data that can be compared with future information to assess how bowfin population dynamics may change in response to harvest. Furthermore, additional studies examining bowfin populations are greatly needed to assess spatial and temporal patterns in population structure and population dynamics and interactions with other members of the fish assemblage.

\section{Acknowledgements}

We thank M. Bowler, S. Gritters, K. Hanson, Z. Jackson, D. Rowe, C. Schnitzler, and M. Stueck for assistance with planning and implementation of this project. Additional thanks to J. Davis, T. Giorgenti, J. Lore, M. Spurgeon, and
S. Wigen for laboratory assistance. We also thank M. Marron for providing UMR harvest data. This manuscript was improved by comments from two anonymous reviewers. Funding was provided by the Department of Natural Resource Ecology and Management at Iowa State University and the Iowa Department of Natural Resources.

\section{References}

Ballard, W. W., 1986: Stage and rates of normal development in the Holostean fish, Amia calva. J. Exp. Zool. 238, 337-354.

Birstein, V. J., 1993: Sturgeons and paddlefishes: threatened fishes in need of conservation. Conserv. Biol. 7, 773-787.

Boreman, J., 1997: Sensitivity of North American sturgeons and paddlefish to fish mortality. Environ. Biol. Fishes 48, 399-405.

Davidson, R. B.; Walker, M. R.; Tilyou, G. A.; Lutz, C. G., 1991: Potential caviar impacts on Louisiana bowfin populations. Proc. Ann. Conf. SEAFWA 45, 385-391.

Davis, J. G., 2006: Reproductive biology, life history and population structure of a bowfin Amia calva population in southeastern Louisiana. Ms thesis. Nicholls State University, Thibodaux, Louisiana.

Daxboeck, C.; Barnard, D. K.; Randall, D. J., 1981: Functional morphology of the gills of the bowfin, Amia calva, with special reference to their significance during air exposure. Respir. Physiol. 43, 349-364

DeVries, D. R.; Frie, R. V., 1996: Determination of age and growth. In: Fisheries Techniques, 2nd edn. B. R. Murphy, D. W. Willis (Eds), American Fisheries Society, Bethesda, Maryland, pp. 483512 .

Dugas, C. N.; Kornikorf, M.; Trahan, M. F., 1976: Stomach contents of bowfin (Amia calva) and spotted gar (Lepisosteus oculatus) taken in Henderson Lake, Louisiana. Proc. La. Acad. Sci. 39, 28 34.

Goodyear, C. P., 1993: Spawning stock biomass per recruit in fisheries management: foundation and current use. Can. Spec. Publ. Fish. Aquat. Sci. 120, 67-81.

Gross, M. R.; Sargent, R. C., 1985: The evolution of male and female parental care in fishes. Am. Zool. 25, 807-822.

Holland, H. T., 1964: Ecology of the bowfin (Amia calva Linnaeus) in southeastern Missouri. Ms Thesis, University of Missouri, Columbia, MO.

Horn, M. H.; Riggs, C. D., 1973: Effects of temperature and light on the rate of air breathing of the bowfin, Amia calva. Copeia 4, 653652.

Hurley, S. T.; Hubert, W. A.; Nickum, J. G., 1987: Habitat and movements of shovelnose sturgeons in the upper Mississippi River. Trans. Am. Fish. Soc. 116, 655-662.

Koch, J. D.; Quist, M. C., 2007: A technique for preparing fin rays and spines for age and growth analysis. North Am. J. Fish. Manage. 27, 782-784

Koch, J. D.; Quist, M. C.; Hansen, K. A., In press. Precision of hard structures used to age bowfin in the upper Mississippi River. North Am. J. Fish. Manage.

Lagler, K. F.; Applegate, V. C., 1942: Further studies of the food of the bowfin (Amia calva) in southern Michigan, with notes on the inadvisability of using trapped fish in food analyses. Copeia, 1942, 190-191.

Lagler, K. F.; Hubbs, F. V., 1940: Food of the longnosed gar (Lepisosteus osseus oxyurus) and the bowfin (Amia calva) in southern Michigan. Copeia, 1940, 239-241.

Mace, P. M.; Sissenwine, M. P., 1993: How much spawning per recruit is enough? Can. Spec. Publ. Fish. Aquat. Sci. 120, 101-118.

Miranda, L. E.; Bettoli, P. W., 2007: Mortality. In: Analysis and interpretation of freshwater fisheries data. C. S. Guy, M. R. Brown (Eds), American Fisheries Society, Bethesda, Maryland, pp. 229-277.

Morrow, J. V., Jr; Kirk, J. P.; Killgore, K. J.; George, S. G., 1998: Age, growth, and mortality of shovelnose sturgeon in the lower Mississippi River. North Am. J. Fish. Manage. 18, 725-730.

Mundahl, N. D.; Melnytschuk, C.; Spielman, D. K.; Harkins, J. P.; Funk, K.; Bilicki, A. M., 1998: Effectiveness of bowfin as a predator on bluegill in a vegetated lake. North Am. J. Fish. Manage. 18, 286-294.

Pflieger, W. L., 1997: The fishes of Missouri, revised edn. Missouri Department of Conservation, Jefferson City, MO. 
Pitlo, J.; Rasmussen, J., 2004: Description of the upper Mississippi River. In: UMRCC Fisheries Compendium, 3rd Edn. J. Pitlo, J. Rasmussen (Eds), Upper Mississippi River Conservation Committee, Rock Island, Illinois, pp. 1-15.

Reed, B. C.; Kelso, W. E.; Rutherford, D. A., 1992: Growth, fecundity, and mortality of paddlefish in Louisiana. Trans. Am. Fish. Soc. 121, 378-384.

Reighard, J., 1940: The natural history of Amia calva (Linnaeus). Mark. Anniversary 4, 57-108.

Scarnecchia, D. L., 1992: A reappraisal of gars and bowfins in fishery management. Fisheries 17(5), 6-12.

Scarnecchia, D. L.; Stewart, P. A.; Power, G. J., 1996: Age structure of the Yellowstone-Sakakawea paddlefish stock, 1963-1993, in relation to reservoir history. Trans. Am. Fish. Soc. 125, 291299.

Scott, W., 1938: The food of Amia and Lepisosteus. Invest. Indiana Lakes Streams 1, 112-115.

Slipke, J. W.: Maceina, M. J., 2001: Fishery analysis and simulation tools (FAST). Version 1.1. Department of Fisheries and Allied Aquacultures, Auburn University, Auburn, Alabama.
Southwick, R.; Allen, T., 2005: The economic benefits of fisheries, wildlife, and boating resources in the state of Louisiana. La. Dept. Wildl. Fish. Rep. Baton Rouge, LA.

Stacy, G. S., III; Smitherman, R. O.; Avault, J. W., Jr, 1970: Food habits of the bowfin in Lacassine National Wildlife Refuge and other locations in Southern Louisiana. Prog. Fish-Cult. 32(3), 153-157.

Van Den Avyle, M. J.; Hayward, R. S., 1999: Dynamics of exploited fish populations. In: Inland fisheries management in North America, 2nd edn. C. C. Kohler, W. A. Hubert (Eds), American Fisheries Society, Bethesda, Maryland, pp. 127-163.

Author's address: Michael C. Quist, Department of Natural Resource Ecology and Management, Iowa State University, 339 Science II, Ames, Iowa 50011, USA.

E-mail: mcquist@iastate.edu 